\title{
Perspicacity of Climate Distinction on Natural Vegetation's in Thar Desert, Pakistan
}

\author{
Sujo Meghwar ${ }^{1}$, G. M. Mastoi ${ }^{2}$, Khalida Faryal Almani ${ }^{3}$, Fouzia Panhwar ${ }^{4}$, \\ Zulfqar Ali Laghari ${ }^{5}$, Khalid Hussain Lashari ${ }^{6, ~}{ }^{*}$, Fahmeeda Memom ${ }^{5}$, Mahjabeen Panhwar ${ }^{7}$, \\ Muhammad Rafique Qambrani ${ }^{8}$ \\ ${ }^{1}$ Department of Geography, University of Sindh, Jamshoro, Pakistan \\ ${ }^{2}$ Institute of Dr M. A Kazi (Chemistry), University of Sindh, Jamshoro, Pakistan \\ ${ }^{3}$ Centre for Environmental Sciences, University of Sindh, Jamshoro, Pakistan \\ ${ }^{4}$ Department of Pharmacology (Faculty of Pharmacy) University of Sindh, Jamshoro, Pakistan \\ ${ }^{5}$ Department of Physiology, University of Sindh, Jamshoro, Pakistan \\ ${ }^{6}$ Department of Fresh Water Biology and Fisheries, University of Sindh, Jamshoro, Pakistan \\ ${ }^{7}$ Institute of Plant Science, University of Sindh, Jamshoro, Pakistan \\ ${ }^{8}$ Centre for Physical Education, Health \& Sports Science, University of Sindh, Jamshoro, Pakistan
}

\section{Email address:}

kh_lashari@gmail.com (K. H. Lashari)

${ }^{*}$ Corresponding author

\section{To cite this article:}

Sujo Meghwar, G. M. Mastoi, Khalida Faryal Almani, Fouzia Panhwar, Zulfqar Ali Laghari, Khalid Hussain Lashari, Fahmeeda Memom, Mahjabeen Panhwar, Muhammad Rafique Qambrani. Perspicacity of Climate Distinction on Natural Vegetation's in Thar Desert, Pakistan. Earth Sciences. Vol. 6, No. 3, 2017, pp. 30-34. doi: 10.11648/j.earth.20170603.11

Received: October 29, 2016; Accepted: December 24, 2016; Published: May 17, 2017

\begin{abstract}
Atmosphere variety in Thar Desert has actuated an expansion in the extent of dry spell. The variety in atmosphere has brought about abatement in characteristic vegetation's. Some plant species are disposed of until the end of time. We have assembled the anthropogenic reaction through a created poll. The information was investigated in SPSS rendition 20. The recurrence information has recommended regular vegetation diminish with the expansion dry season a great scale. The anthropogenic reactions demonstrate high effect of environmental change on vegetation's. The recurrence information, we have gathered, gives knowledge into the comprehension a relationship between environmental change and normal vegetation.
\end{abstract}

Keywords: Drought, Anthropogenic, Magnitude, Thar Desert, Vegetation's

\section{Introduction}

The quantity of physical components bolster environment, the Desert secured one seventh area surface around world. The lack of dampness in desert inceptions to the diffusing vegetation. This prompts precariousness precipitation and dissipation rate and it is come about aridity (Melillo, 1993; Schlesinger, 1990; Prabhu, 2004; Khan, 2001; Poonia, 2013). The tropical area regions practically covers desert belts. Thar Desert situated at tropic of Cancer in northern side of the equator and it's property region $22000 \mathrm{~km}^{2}$, which has sensational atmosphere changes (khan, 2015; Khan, 2012; Ghalib, 2008).
Atmosphere variety is connected with the expansion of dry season by the effect of summer storm, occasional wind, precipitation rate and the kind of characteristic vegetation, which have been influenced subsequent to the antiquated atmosphere somewhere in the range of 18,000 to 20,000 years back (Ivanocheko, 2004; Prabhu, 2004; Sarkar, 1990) That demonstrates the rainstorm precipitation has acquired a major variety Thar desert in twentieth century because of the custom of atmosphere variety, which could be brought about of atmosphere change (Iyengar,2004; Sharma, 2010). As of late impact of atmosphere variety in the finishing of 21 century as presentation by Between Legislative Board on Environmental Change (IPCC) has exacerbate over desert 
district and Thar Desert is considered delicate which is jeopardized to intense precipitation and incessant dry spell (Gasp and Maliekel, 1987; Poonia 2013).

The tough atmosphere variety and physiographic changes demonstrates an immeasurable change in common vegetation. Absolutely, there is classical asset scattered.
Primitive time, increment of anthropogenic exercises utilized vegetation for fuel it has brought about the unsettling influence in physiographic setting. As of late, the atmosphere variety and less precipitation have brought intense lack of common vegetation (Figure 1) (Sharma, 2010; Poonia, 2013).

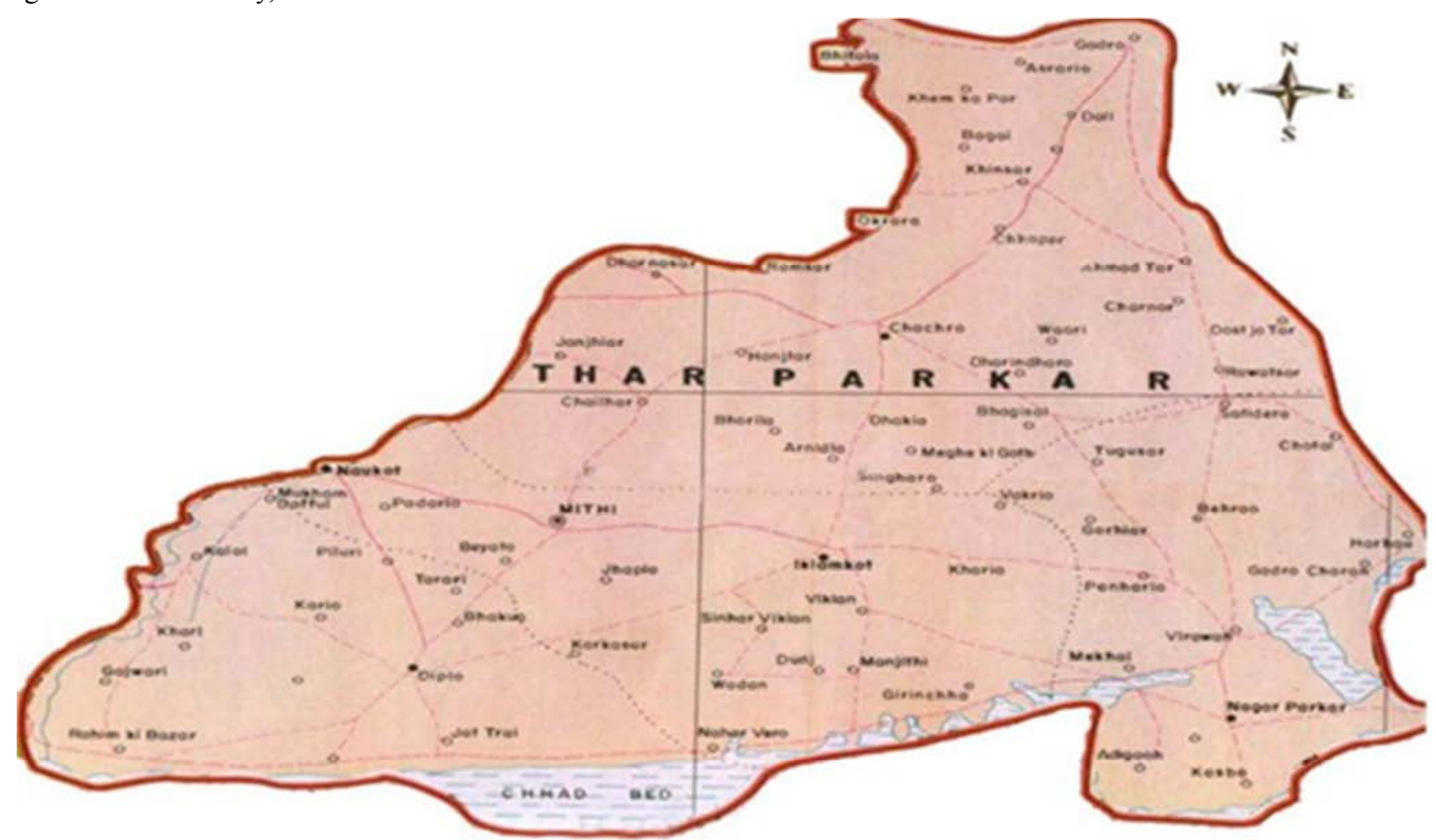

Figure 1. Location map of the study area.

\section{Research Methodology}

Atmosphere variety is connected with the expansion of dry spell by the effect of summer storm, occasional wind, precipitation rate and the kind of characteristic vegetation, which have been influenced subsequent to the old atmosphere around 18,000 to 20,000 years prior (Ivanocheko,2004;, Prabhu, 2004; Sarkar, 1990) That demonstrates the rainstorm precipitation has gotten a major variety Thar desert in twentieth century because of the convention of atmosphere variety, which could be The study territory information dissected through review poll of 234 people. The survey appropriated in 53 towns and Towns of contrast part in Thar Desert that nearly covers the impression of entire study territory. The impression of individuals showed dry season increment brought about decline of characteristic vegetation. The remaining of temperature exhibit the variety of atmosphere. SPSS (factual Bundle for Sociology) used to investigated the study survey information, the measurable centrality was settled at 0.05 level. Since customarily this level of measurable criticalness has been seen to be trailed by the greater part of specialists who utilize the make of factual recurrence.

\section{Drought Caused Vegetation Dispersal}

Large part of analysts who utilize the make of measurable recurrence. Atmosphere variety is connected with the expansion of dry spell by the effect of summer storm, regular wind, precipitation rate and the kind of characteristic Every single dry area are subjected to expand, which is being brought about of dispersal of key plant species, however the worldwide temperature (GT) and dry spell increment. is expanding colossally, in ordinarily the area climate is corresponded with surface temperature (ST), which uncovers the corruption of area surface and reduction of lessening of vegetation because of increment of dry season at enough level of scale (Wagner, 1996; Melillo, 1993,). Subsequently, high surface temperature (ST) expanded idle evapotranspiration speed is welcome to build dry succession. This is a major loss of vegetation, since vegetation is specifically related with dry season (Schlesinger, 1990). The Thar Desert populace has 71 reacted the temperature has expanded brought about dry spell rate is expanded. This recommended dry spell has affected to scattered vegetation (Figure 1). 


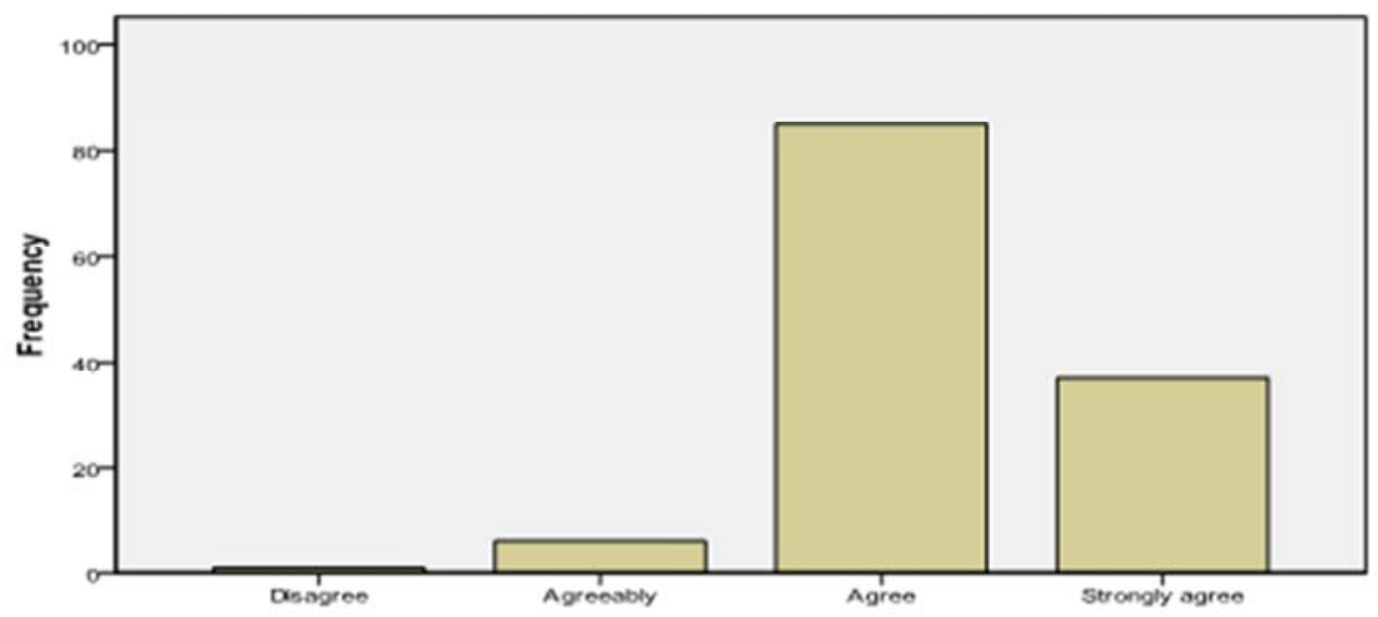

Figure 2. Anthropogenic respond of increasing temperature caused decreasing vegetation.

The past studies recommended the landmass of Thar desert can be shaped amazing ascended of temperature the day temperature could be recorded all the more then $40 \mathrm{oc}$ amid all mid year seasons. (Fontugne, 1986, Borole, 1982, Prabhu, 2004; Sarkar, 1990). The most extreme atmosphere variability happens in Thar Desert reflected the increase of drought.

Table 1. Represent drought scale

\begin{tabular}{ll}
\hline SPI values & Drought category \\
\hline 0 to -0.99 & Mild drought \\
-1.00 to- 1.49 & Moderate drought \\
-1.50 to- 1.99 & Severe drought \\
$<-2.00$ & Extreme drought \\
\hline
\end{tabular}

Source: Mckee, 1993

\section{Drought Induce Degradation of Natural Vegetation}

This locale was the most noticeably bad rate of dry spell increment and the most exceedingly bad rate of dry spell was1952-1956. The twenty century was confronted extreme happened in just about decades 1901-10, 1911-20, 19321940, 1961-70, 1981-90 and 2001-2006, while, moderate and serious dry spell recurrence were varied 1-5 years in this district (Rao, 1970). The atmosphere variety is practically happened on northern half of the globe, in an especially subtropical, hence, Thar desert is intensely influenced by this atmosphere variety (Swanson, 1999), it is created of decrease vegetation and came about the rises and sand sheets are presently destabilized (Swanson, 1999).

\section{Result}

The Atmosphere information of Thar desert showed that yearly surface temperature is expanding in the arrangement of 1.75 to $2.5^{\circ} \mathrm{C}$ from 1.5 to $2.25^{\circ} \mathrm{C}$ in winter, that stretches out in summer 2 to $2.5^{\circ} \mathrm{C}$, that uphold the precipitation is lessened in yearly standard by $5-25$ rate (Ragab, 2001). The yearly temperature of are spoken to be shifted on account of physical environment, for example, Arabia ocean, Runn of Kutch, Indus waterway, these are the fundamental wellspring of atmosphere variety in this locale.

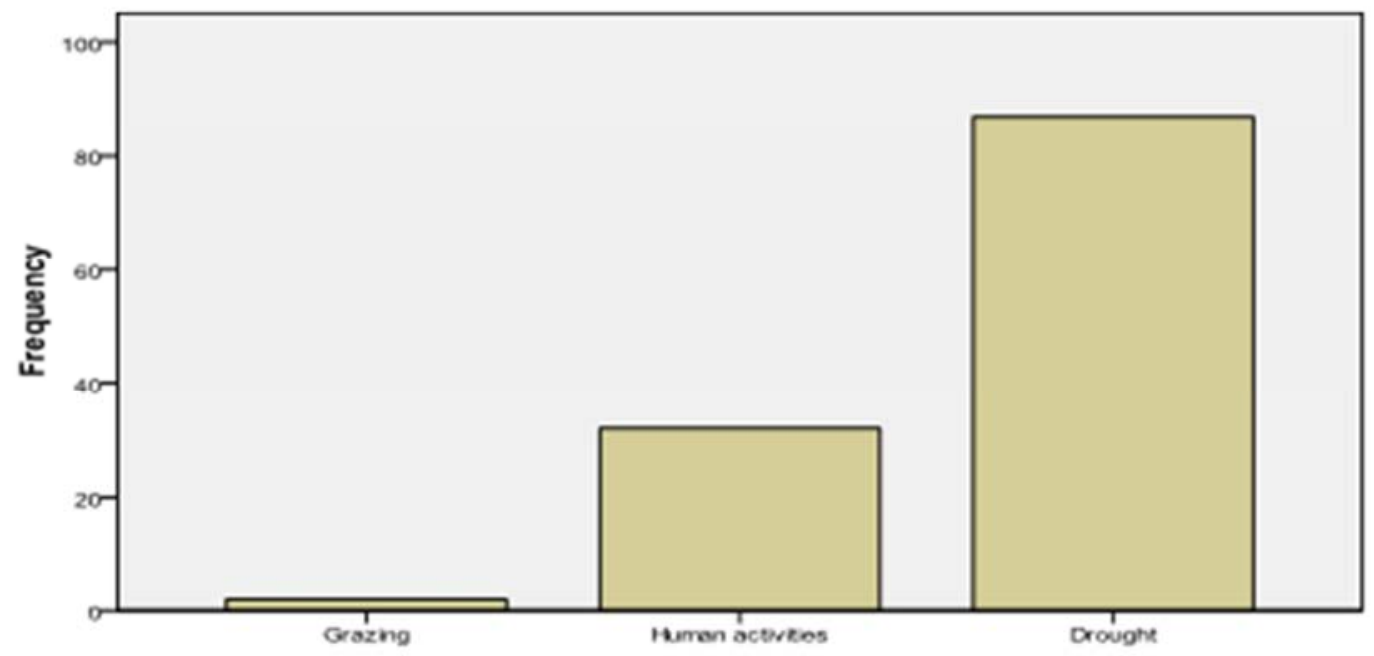

Figure 3. Drought caused of decreasing vegetation. 
The main result which indicates view of individuals about vegetation that number of components connected with abatement in vegetation. We notwithstanding, set up to investigate the view of individuals living in the region about conceivable variables, bringing on reduction in vegetation. Dry spell was reacted by individuals as the central point took after by human exercises. Our study is in comprise on with the vitally distributed studies. Which is additionally demonstrated dry season as the primary variables. The past studies bolstered atmosphere brought about dry spell has scattered vegetation (Khan, 2001; Poonia, 2013

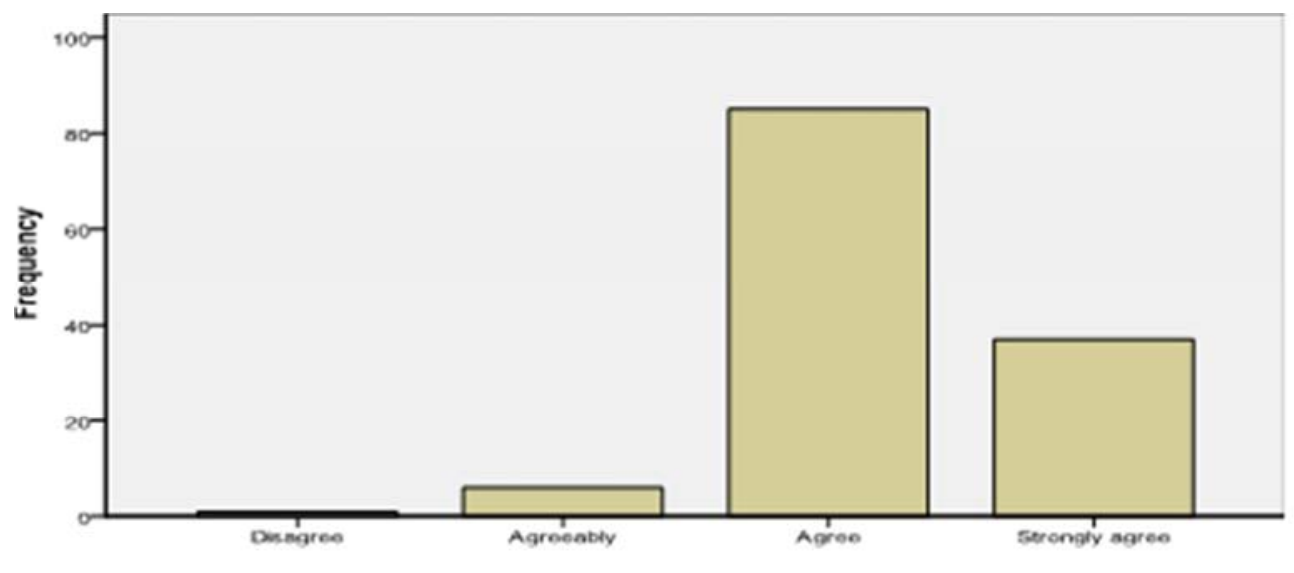

Figure 4. Drought increase and vegetation decrease.

Be that as it may, for the most part the dry season recurrence was expanded from sixteenth century and it broadened monstrous amid eighteenth, nineteenth and twentieth century (Juyal, 2006) in this district, while a normal mean precipitation between 1950-2004 of Badin $235 \mathrm{~mm}$ and Chhor $219 \mathrm{~mm}$, which was diminished from normal mean of 508-1016mm over all Thar desert from19th century (Shamshad, 1988), this diminishing proportion shows the eminent dry season. Which is a noteworthy wellspring of diminishing vegetation. The quantity of individuals reacted of dry season is a noteworthy reason for diminishing vegetation. The dry season is an exceptionally normal because of high rate of precipitation vacillation. since atmosphere variety is principle component of Thar desert, this variety makes conceivable route for happening dry spell, subsequently following 5-6 years dry spell happens two year and in the dry spell year. More than 66 rates individuals concurred that dry season has brought on decline vegetation 29 rates have firmly conceded to the dry season as main consideration of diminishing vegetaion (Figure 3). Dry season has been seen as principle component in our studies region with past studies on recognition about dry spell as an element (Khan, 1960; Meher, 1980; Pillar, 1993; Poonia; Haigis, 2000; Wezel, 2013)

\section{References}

[1] Armond, A. Paul and et al, 1978, Photosynthetic Acclimation to Temperature in the Desert Shrub, Lar read divaricates, Plant Physiology 61, 411-415.

[2] Borole, D. V., Kameswara, KR., Krishn amurthy, R. V. and Somaya julu, B. L. K. (1982) Late Quaternary faunal change in coastal Arabian Sea sediments. Quaternary Research, 18 (2), 236-239.

[3] Fontugne, M. R. and Duplessy, J. C. (1986) Variation in the monsoon regime during the upper Quaternary: Evidence from carbon isotopic record of organic matter in north Indian Ocean sedi.

[4] Ghalib, S. A., khan, A. R., zehra, A. and Abbas, A., 2008. bioecology of nara desert wildlife sanctuary, districts ghotki, sukkur and khairpur, sindh. pakistan j. zool., 40: 37-43.

[5] Hu Jen Chang, 2000, the Indian Summer Monsoon, Geographical Review, Vol. 57, No. 3.

[6] Ivanocheko, S. Tara, 2004, Regional environment and description of Proxies (PhD thesis, ch. 1), School of Geosciences, Grant Institute, University of Edinburgh, UK, 13-16.

[7] Iyengar, R. N., 2004, Description of rainfall variability in $\mathrm{Br}$ hat-samhitaofvaraha-mihira, Current Science, Vol. 87, No.4, 531-533.

[8] Juyal, N. and et al, 2006, Continental record of the southwest monsoon during the last $130 \mathrm{ka}$ : evidence from the southern margin of the Thar 9. Desert, India, Quaternary Science Reviews 25, 2632-2650.

[9] Khan, W. M. A and Gupta, A. C., 1960, Plant commonnities associated with Sal (Shorearobusta). Regeneration in Dehradun valley. Indian Forester, 86: 417-421.

[10] Khan, T. I. and Frost, S.: 2001, 'Floral Biodiversity: A Question of Survival in the Indian Thar Desert,' The Environmentalist 21 (3), 231-236.

[11] KHAN, A. A., 2012. Bio-economic impacts of vertebrate pests on crops with special reference to rodent pests in Pakistan.

[12] Khan, A. A., Khan, W. A. and Chaudry W. A.,2015, Mammalian Diversity in Thar Desert Habitat of Tharparkar District, Sindh, Pakistan, Pakistan Journal of Zoology., vol. 47 (5), 1205-1211.

[13] Meher, H., 1980, The Thar Desert -its climatic history. Man and Environment. 4: 1-7. 
[14] Melillo, J. M. and et al, 1993, Global climate change and terrestrial net primary production, Nature 363, 234-240.

[15] Pant, G. B. and Maliekal, J. A., 1987. Holocene climatic changes over north-west India. An appraisal, Climate Change10, 183-194.

[16] Pillar, D. P. and Orloci,L., 1993, taxonomy and perception in vegetation analysis, Coenoses 8 (1) 66.

[17] Poonia, S. and Rao A. S., 2013, Climate Change and Its Impact on Thar Desert Ecosystem, Journal of Agricultural Physics, Vol. 13 (1) 71-79.

[18] Prabhu, C. N.,Shankar, R.,'Anupama, K., Taieb, M., Bonne fille, R., Vidal, L. and Prasad, S. (2004) A200-kapollen and oxygen-isotopic record from two sediment cores from the eastern Arabian Sea. Palaeogeography, Palaeoclimatology, Palaeoecology, 214 (4), 309-321.

[19] Ragab, R. and Prudhomme, Ch. (2001) Climate change and water resources management in arid and semi-ari dregions: Prospective and challen gesfor 21 stcentury. Bios ystemsen gineering, 81 (1), 3-34.

[20] Rao, R. S., 1970, Studies on the flora of Kutch, Gujarat State, India and their utility in the economic development in the semi arid region. Annals of Arid Zone 9, 125-142.

[21] Roy, P. D. and Kloss-smykatz. W., 2005, REE geochemistry of the recent playa sediments from the Thar desert, India: An implication to playa sediments provenance, Chemie deride Geochemistry, 67, 55-68.
[22] Sarkar, A., Ramesh, R., Bh attachara, S. K. and Gajagopalan, G., 1990 Oxygen isotope evidence for a stronger winter monsoon current during. Nature, 343,549551 .

[23] Schlesinger, W. H. and et al, 1990, Biological Feedbacks in Global Desertification, Science 247, 1043-1048.

[24] Shamshad, K. M., 1988, The meterology of Pakistan, Royal Book Company, Karachi, Pakistan.

[25] Sharma, K. K. and Pandey A. K., 2010, Phytosociological study of vegetation of some selected arid region of the Thar Desert of Rajasthan, India, Current World Enviornment; Vol.5 (1),51-58

[26] Swanson, F. and et al, 1999, Evaluating the usefulness of natural variability in managing ecological systems, Ecological Applications, November, Vol. 9, No. 4, 1179-1188.

[27] Wagner, E. L. and Gleeson T. T., 1996, low temperature and exercise recovery in the desert iguana, Physiol. Zool., 168190.

[28] Wezel, A.; Haigis, 2000, Farmers' perception of vegetation changes in semi-arid Niger, Land degradation and Development, Vol.11 (6) 523-534.

[29] Gregory, A. T., R. M. Armstrong, et al. (2006). "Rural and remote health in Australia: How to avert the deepening health care drought." Med J Aust 185 (11-12): 654-660. 